\title{
José Santos Chocano y. su "Alma de América"
}

POr ALBERTO TAURO

Grande fue la sorpresa de Don Quijote, cuando supo que los duques habían decididoconfiar, nada menos que el gobierno de una ínsula, a su leal y humilde escudero. Muy discretamente lo condujo assu aposento, para instruirlo en los principios que la prudencia aconseja aplicar en el ejercicio de las funciones inherentes a tal cargo. $Y$ de paso le dio a conocer la amargura que lo había embargado, al ver que sus esforzados desvelos no le habían franqueado hasta entonces la oportunidad de premiar sus servicios; así como el desconcierto que invadía su ánimo, al advertir que sin pretenderlo y quizá sin poseer las cualidades indispensables, Sancho se veía exaltado a la posición que vanamente piden muchos. "Otros cohechan, importunan, solicitan, madrugan, ruegan, porfían, y no alcanzan lo que pretenden; y llega otro, y sin saber cómc ni cómo no, se halla con el cargo y oficio que otros muchos pretendieron". Y viene este episodio a nuestra memoria, porque alguna semejanza guarda con lo ocurrido a muchos investigadores, que dedican largos y pacientes afanes a la búsqueda de testimonios, a la comprobación de datos o teorías, a la plena integración de informes o argumentos; con plena conciencia de sus hallazgos y sus inferencias legítimas, apun- 
tan cuanto puede ser objeto de rectificación o de posterior ampliación, señalan derroteros de posible fecundidad, sugieren bases para nuevos y metódicos escrutinios; y, no obstante, puede ocurrir que por azar descubre otro un importante destello de la verdad que antes se mostró esquiva, un desconocido elemento que da firmeza a hipótesis previas, una noticia merced a la cual se perfecciona una secuencia. La suerte puede lograr, a veces, los efectos que la constancia y el mérito no alcanzan. Muy claramente lo confirma así nuestro casual encuentro de la versión inicial de Alma América, la obra que con mayor intensidad define el modo poético de José Santos Chocano y las vetas de su inspiración, y que no conoció Luis Alberto Sánchez, a pesar de las amplias, sagaces y dilatadas inquisiciones que lo llevaron a penetrar en los secretos de la vida y la labor creadora del eminente poeta.

\section{CRONOLOGIA ALUSIVA}

La versión inicial de Alma América apareció en la edición de El Comercio, de Lima, correspondiente al $1^{\text {? }}$ de noviembre de 1903. O sea, tres años antes de que el libro fuera impreso en España. Y durante este lapso sufrió adiciones, supresiones y enmiendas, que determinaron una fundamental alteración de los esquemas a los cuales obedeció la proyección del autor, y que revelan ampliamente las orientaciones de su trabajo lírico.

Esa primera publicación incluye una dedicatoria - compuesta en doce "quintetos (c), y cuarenta sonetos; pero en ella se anuncia que "el libro consta de cien sonetos ya escritos", y declara el poeta que su selección incluía cuanto deseaba dar entonces a la publicidad - tal vez porque los sonetos restantes debían ser sometidos a revisión y nueva elaboración-. Es posible que enviara ejemplares del diario respectivo a sus amigos de Europa y América, para mantener fraterno intercambio y excitar su aplauso. En particular, recibió generosa y amigable respuesta de don Miguel de Unamuno, quien ofreció a José Santos Chocano escribir un prólogo para el anunciado libro. Y al agradecer tan auspicioso gesto, en una nueva misiva (1:-X-1904), apuntó el caudaloso poeta dos revelaciones: 1 a, "he suprimido lo que Ud. me indicó y he atendido aquellas observaciones que Ud. hizo a los cuarenta sonetos que le envié"; y $2^{3}$, "mi libro es ya seis veces lo que Ud. conoce". Por tanto, reconoce haber hecho supresiones y correcciones, en armonía con las sugestiones del recio ensayista, y haber aumentado hasta 240 el número de sonetos y "poe- 
mitas" que debían integrar Alma América. Pero todavía "no dejaba de preparar la que consideraba su obra máxima" - según lo establece cabalmente Luis Alberto Sánchez - En verdad, continuaría aún enriqueciendo y decantando las arrogantes creaciones de su madurez, porque debía volcar en su libro las impresiones alentadas en Centro América y Colombia, durante su viaje a través de Chile y Argentina, y durante su estancia en España. "En el Magdalena" y mientras corría el año 1904, escribió "para La Ilustración Española y Americana" un soneto, que tituló El arpa del jaguar y en la cdición definitiva del libro integraría precisamente el caleidoscópico Canto al Magdalena. "A bordo del Atlantique" y a la vista de Buenos Aires, compuso otro soneto en homenaje a Juan de Garay, que el 25 de mayo de 1905 dio a conocer en el curso de una fiesta conmemorativa de la independencia argentina. Y aunque a mediados de aquel año puso en manos de Unamuno el texto "completo", es posible que todavía no hubiera escrito los poemas que abren el libro - A. S. M. C. Don Alfonso XIII, y Ofrenda a España- y que dio a conocer el 19 de noviembre de 1905, durante la velada que ofreció en el Ateneo de Madrid ${ }^{1}$.

Alma América es, sin duda, un poemario escrupulosamente cuidado. Sus composiciones fueron sometidas a una incesante revisión verbal y métrica. En forma documentada y emotiva revela los valores que distinguen a la gesta histórica y la naturaleza del continente. $\mathrm{Y}$ aunque su resonancia puede parecer ostentosa y ligera, es claro que propaga los alientos de una pasión entrañable, cy quelenollossadquiere carácter y sentido la propia existencia del poeta. De allí su legitimidad y su feliz permanencia.

\section{TITULO}

Profunda diferencia existe entre las dos modalidades que reviste el título del libro, en la versión primaria y en la edición definitiva. La supresión del nexo y la adjetivación del sustantivo inicial, implican cambios muy apreciables en la

(1) Es obvio que durante esos años, caracterizados po: la sucesión de intensas vivencias, no cesó el poeta de revisar y enriquecer los cien sonetos que originalmente integraron su obra. Particularmente lo comprueban los dos poemas que insertamos al final, cuyos manuscritos originales posee Antonio Rodriguez Noñino, y de los cuales obtuvimos copias fotostáticas merced a la gentil intercesión de Luis Monguić, Son ellos EI arpa del Jaguar y Selvática. Permiten advertir que habia superado la estricta limitación a los moldes del soneto, tal vez para :evelar, en la variedad de las formas poéticas, las múltiples sugestiones de la naturaleza y la historia americanas; y que manteniendo la inicial formulación del tftulo, expresaba su emoción ante el descubrimiento de las esencias hasta entonces inadva:tidas. 
actitud espiritual y la voluntad creadora del poeta. Y así lo intuye Luis Alberto Sánchez, cuando reflexiona que "su título no proviene de una presentación o descripción del alma de América, sino más bien, de una identificación de su persona con América, o sea que, si alguna otra locución está más cerca, dicho título es el América de mi alma". Exactamente: abandona el poeta su deslumbramiento ante la espléndida y pintoresca naturaleza americana, para enderezar su emoción hacia las perspectivas que ella ofrece a la humanidad; mantiene su admiración por la gallardía individual de los conquistadores, pero también comprende la grandeza que diariamente prodigan cuantos labran el destino del continente; y comunica un mensaje, al mismo tiempo que destaca su gusto por la cadencia eufónica y la novedad de la expresión.

También se registra un cambio significativo en el subtítulo: "sonetos continentales" primero, y, finalmente, "poemas indo-españoles". De una parte advierte su adhesión al troquel herediano, como forma adecuada para dar a su visión las precisas aristas de una joya; y por otra, deja suponer que sus vuelos líricos demandan las imprevistas posibilidades de las combinaciones métricas sin un límite previo. Denota, por añadidura, que al dar a la estampa su visión inicial sólo deseaba exaltar los temas unitarios del Nuevo Mundo; y luego prefirió destacar el dualismo fundamental de la formación histórica americana, para ligar su inspiración con las tradiciones hispánicas y auncreivindicar su entroncamiento con viejos hidalgos. El afán descriptivo, que podía ceder a la captación de una escena inmovilizada por la admiración del pueblo, evoluciona hacia el examen espectral, hacia la identificación de los elementos que viven en el alma americana; es decir, que a la postre canta en la unidad de América el fruto renovado de la conciliación y el equilibrio.

\section{DEDICATORIA}

Corta y promisora como la primera salida que llevó a Don Quijote hasta la venta donde fue armado caballero; así fue aquella que José Santos Chocano efectuó con los "sonetos continentales" en cuyos versos había intentado cultivar el Alma de América. Y pulía sus estrofas con amor, mientras aguardaba en su vigilia el anuncio del espaldarazo deseado. Que para eso, sin duda alguna, había inscrito bajo el título unas palabras que debían atraer favorables auspicios: "A José María de Heredia, rey del soneto y nacido en las 
Antillas, dedico este libro de sonetos indianos". Luego le advierte humildemente que llega hasta él con la quebrada voz de sus versos, para hacerle escuchar los lejanos ecos de su nativa América - donde "un cantor, bregando entre cadenas, te da su nombre y su vibrante lira"-, le sugiere que se inspire en la historia y la belleza naturales que seguramente arrullaría en el fondo de su conciencia, y, sin hesitar ya, requiere la benévola consagración:

Desde hoy, Maestro, ampárame en tu coro, la sombra de la rubia palma.

Tú pondrás sobre mí tu sello de oro;

y yo pondré en tu cántico sonoro

itodo este fuego que te incendia el alma!

¿Respondió el celebrado vate a la petición del novel can tor de América? ¿O la contempló en su gabincte, un día tras otro, en espera de la quietud que le permitiera modular satisfactoriamente sus acentos, y la muerte frustró la realización de tal deseo? Es difícil determinarlo. Pero quizá dejó en suspenso la misiva gratulatoria y el aplauso, porque había algo de irrespetuoso y desafiante en aquel homenaje. En verdad, no debió gustar a José María de Heredia el desplante ensayado por José Santos Chocano, en cuanto pretende poner fuego en el cántico de su maestro, que él admira en su perfección formal pero implícitamente juzga tan frío como el mármol.

Lo cierto es que el poeta se vio impelido a fijar en otro horizonte su mirada, cuando quiso hacer de Alma América una trascendente muestra de pleitesía. Y, decepcionado tal vez por el silencio que ante su "vibrante lira" guardara el "rey del soneto", o movido hacia más eficaces devociones por el hecho de haber cumplido aquel su trayectoria vital, dirigió su mirada hacia la católica majestad del rey Alfonso XIII. Según la misma estrategia, ofrece su poesía como un tributo, expone la variada y multiforme significación de su contenido, e insinúa el don que en reciprocidad desea. Pero su actitud es ahora cortesana, y no espera ya un lírico espaldarazo, sino una objetiva muestra de mecenazgo. En efecto, parece ensayar una reverencia cuando dice

Yo que ni exploro bosques ni otras ciudades fundo, os quiero dar la América intacta en mi canción; que os puede hacer más dueño de nuestro Edén fecundo la lengua de Cervantes que el barco de Colón. 
Enumera luego los motivos que en sus versos desfilan, compara su inspiración con las energías de la naturaleza autóctona, y -mirando "a Cervantes como el mejor virrey" - anuncia al soberano la rendida prosternación de su musa: "una salvaje"

que se echará de hinojos ante el poder real.

Os tomará la diestra y os besará en el sello

y bastará, que en cambio, le déis para su cuello apenas una sarta de cuentas de cristal...

Por tanto, pueden advertirse profundos cambios, desde que José Santos Chocano ensayó, en Alma de Améríca, la exaltación de las galas naturales y los valores históricos del continente, hasta que decidió interpretar, en Alma América, el afecto y la admiración que hacían bullir en su espíritu. Afectan a las concepciones temáticas, las formas poéticas y la actitud humana. De allí el interés que puede revestir la confrontación de ambos textos.

CONTENIDO

Aparte de los bizarros quintetos en los cuales expresó su dedicatoria, José Santos Chocano eliminó doce de los cuarenta sonetos que ofreció, al efectuar la publicación tentativa del poemario que tituló $A L M A D E A M E$. RICA, a saber: La partida de Colón, El Amazonas, Marina tro. pical -anteriormente aparecido Cen el semanario Actualidades: Lima, 30-VI-1903 -, La fauna de América, La ceiba, Muerte de jaguar, La noche triste, Ante un huaco, Las huacas, Dama limeña, El Virrey galante y El guajiro.

De los veintiocho sonetos que merecieron ser reproducidos en Alma América, únicamente tres aparecen sin alteraciones textuales: Las punas, Panamá y Campesina costarri. cense. Seis experimentaron tan sólo el cambio de una palabra: Las selvas, Los pantanos, En el Canal, El añil, La danta sorprendida y El Paseo de Aguas. Cinco lucen modificaciones titulares: bien, mediante simples supresiones, como en $E l$ sueño del boa, El sueño del cóndor y El sueño del caimán, que aparecen como $E l$ boa, El cóndor y El caimán, respectivamente; bien, mediante la agregación de voces que precisan la compresión, como en Panamá y El Niágara, que han de ser El istmo de Panamá y Las cataratas del Niágara. En cuanto a las correciones introducidas en los restantes, pueden limitarse a veces a las inflexiones verbales o la calificación; pero alcanzan una extremosa y reveladora amplitud en Las dos rayas, 
cuyos endecasílabos resultaron estrechos para dar adecuada expresión a los nuevos contornos del episodio evocado, y hubieron de ser trocados por alejandrinos. Y, si a esta observación se asocia el hecho de aparecer en la edición definitiva de Alma América hasta veinticinco sonetos escritos en metro de catorce sílabas, podrá advertirse que durante la preparación de este libro se define la adhesión de José Santos Chocano a las concepciones innovadoras del modernismo.
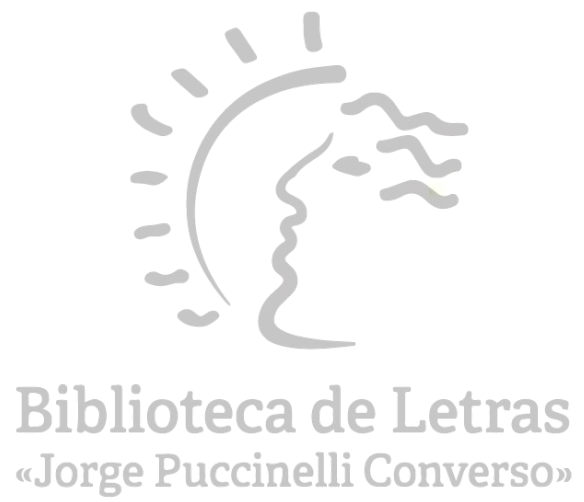


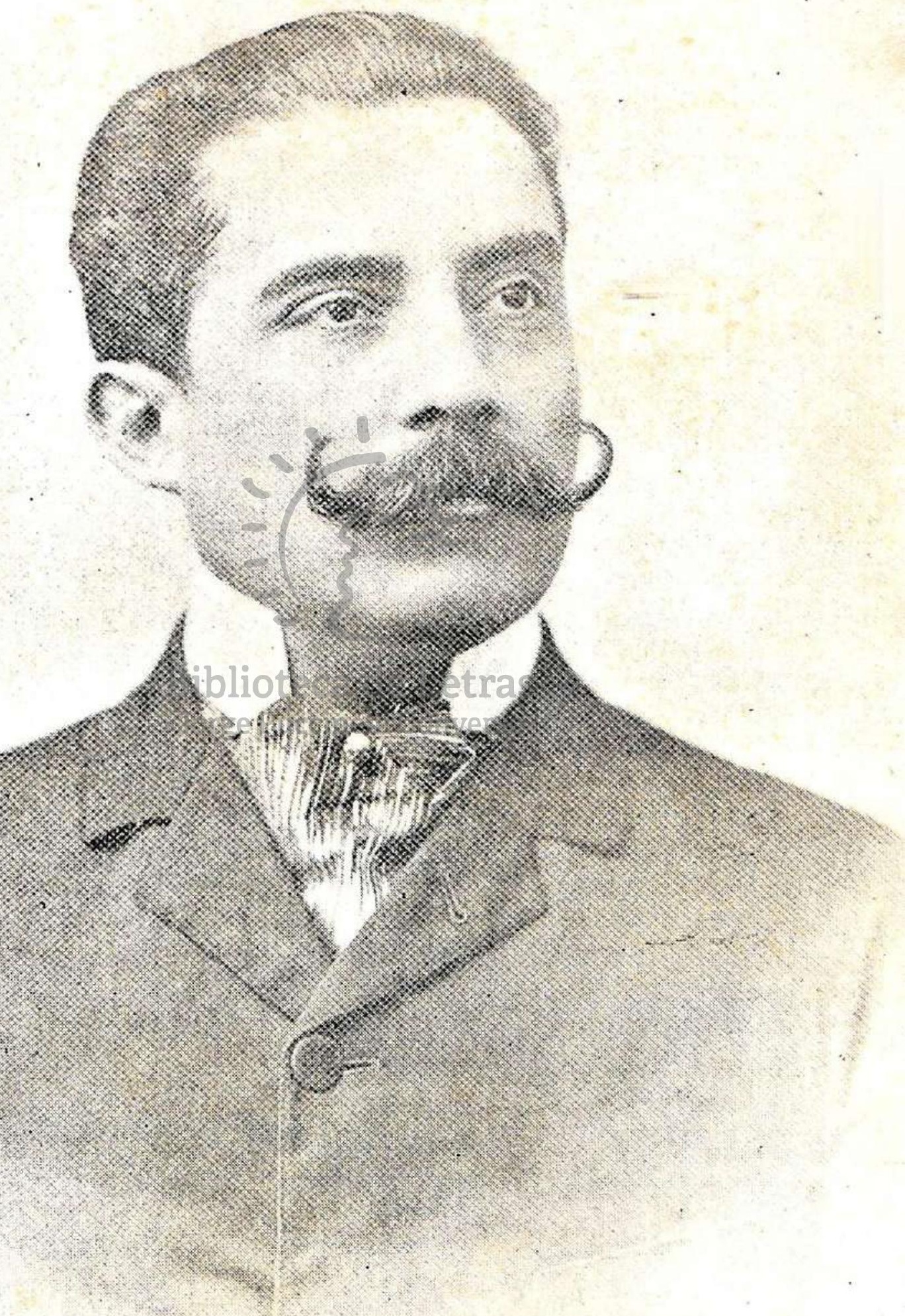



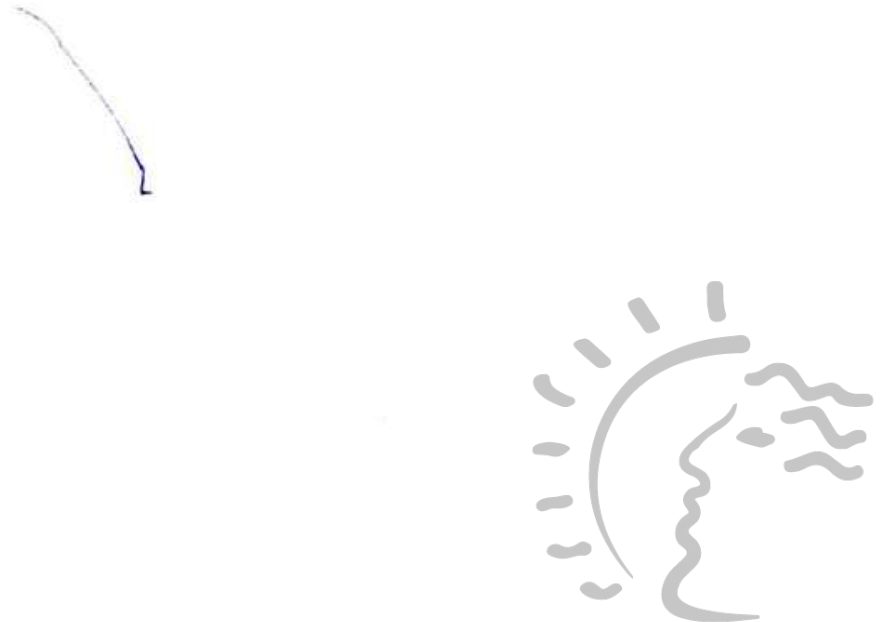

Biblioteca de Letras
"Jorge Puccinelli Converso"

José Santos Chocano 